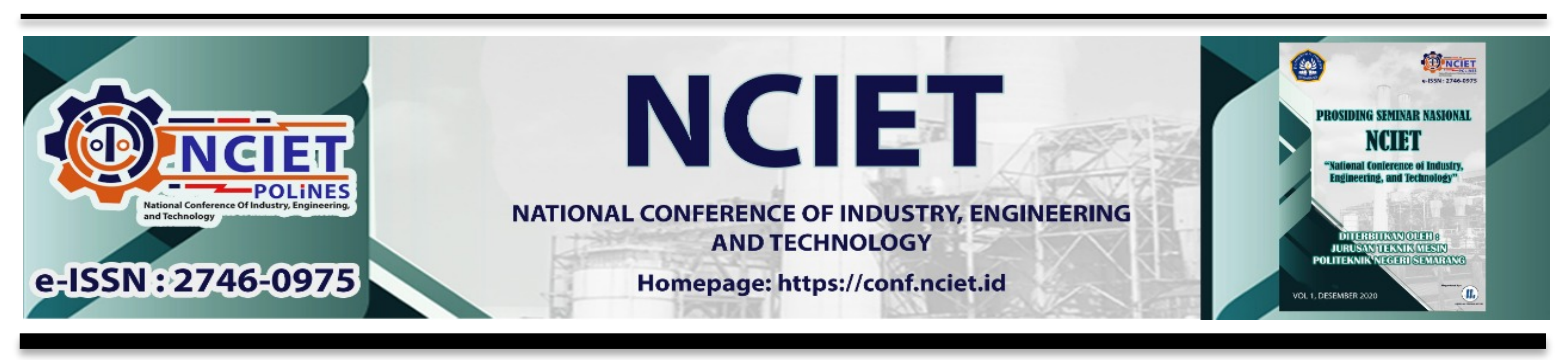

Prosiding Seminar Nasional NCIET Vol.1 (2020) B170-B181

$1^{\text {st }}$ National Conference of Industry, Engineering and Technology 2020,

Semarang, Indonesia.

\title{
POTENSI KECEPATAN PEMBENTUKAN SLAGGING DAN FOULING PADA BOILER PLTU BERBAHAN BAKAR BATU BARA
}

\author{
Muna Indrayana Saputra*, Ika Yuliyani \\ Jurusan Teknik Konversi Energi, Politeknik Negeri Bandung \\ Jl. Gegerkalong Hilir, Ciwaruga, Parongpong, Kabupaten Bandung Barat, 40559 \\ *E-mail: munaindras@gmail.com
}

\begin{abstract}
Abstrak
Batubara merupakan bahan bakar yang umum digunakan pada Pembangkit Listrik Tenaga Uap (PLTU). Batubara sendiri memiliki karakteristik atau kandungan yang dapat menentukan kualitas dari batubara tersebut. Untuk mengetahui kualitas dan kandungan dari batubara dapat dilakukan melalui beberapa analisa, seperti analisis proksimat dan ultimat. Karakteristik dan kualitas batubara akan mempengaruhi proses pembakaran pada boiler seperti nilai panas yang dihasilkan dan juga terhadap pembentukan partikel-partikel hasil pembakaran, seperti residu/abu. Proses pembakaran batubara dan udara pada ruang bakar boiler PLTU akan menghasilkan panas dan juga terbentuknya residu abu yang tidak dapat dihindari, dan memiliki potensi terhadapap pembentukan kecepatan slagging dan fouling. Potensi kecepatan pembentukan slagging dan fouling pada boiler dapat diketahui dengan melihat hasil dari analisi kandungan batubara yang digunakan, sehingga jenis batu bara yang berbeda karakteristik akan menentukan kecepatan pembentukan slagging dan fouling yang berbeda. Perhitungan indeks potensi kecepatan pembentukan slagging dan fouling dapat diketahui dengan beberapa parameter seperti nilai rasio basa-asam untuk potensi slagging pada jenis batubara abu bituminus, ash fusion temperature untuk jenis batubara abu lignit dan viskositas untuk jenis batubara abu bituminus dan lignit. Perhitungan indeks fouling menggunakan fouling factor untuk jenis batubara abu bituminus dan berdasarkan kandungan $\mathrm{Na} 2 \mathrm{O}$ untuk abu lignit. Hasil analisis yang dilakukan menunjukan penggunaan batubara deangan jenis abu lignit lebih meningkatkan indeks potensi pembentukan slagging dan fouling pada boiler dibandingkan batubara dengan jenis abu bituminus.
\end{abstract}

Kata Kunci: Batubara; pembakaran; Indeks Slagging; Indeks Fouling

\section{PENDAHULUAN}

Pada Pembangkit Listrik Tenaga Uap (PLTU), boiler merupakan bejana tekan yang berfungsi untuk mengubah air menjadi uap bertekanan dan bertemperatur tinggi. Dalam proses perubahan tersebut maka dibutuhkan energi panas yang dihasilkan dari proses pembakaran bahan bakar yaitu batubara. Batubara memiliki karakteristik yang berpengaruh terhadap kualitas batubara, karakteristik tersebut dapat diketahui melalui analisis proksimat dan ultimat. Analisis proksimat digunakan untuk mengetahui kadar air (moisture), kadar abu (ash), zat terbang (volatile matter), dan kadar karbon (fixed carbon). Analisi ultimat 
digunakan untuk mengetahui unsur mineral antara lain karbon, hidrogen, nitrogen, sulfur dan oksigen. Selain itu ada juga nilai kalor (caloric value), tingkat ketergerusan, serta caking dan coking coals (K. rayaprolu. 2009). Nilai tersebut diatas akan berbeda pada setiap batubara tergantung pada kualitas dan asal batubara (Jian bo li, 2016). Pada sebagian besar PLTU, batubara yang digunakan pada proses pembakarannya mempunyai kualitas yang berbeda-beda. Dalam hal ini, pasokan batubara tidak tetap dari hanya satu tempat penambangan saja. Sehingga sering dilakukan blending atau pencampuran batubara yang akan digunakan pada proses pembakaran.

Batubara sebagai bahan bakar, pada saat pembakaran kualitas batubara akan mempengaruhi proses dan hasil pembakarannya. Pembentukan residu abu tidak bisa dihindari saat pembakaran batubara, pembentukan residu abu merupakan salah satu hasil pembakaran selain panas yang berguna untuk memanaskan air. Selama proses pembakaran dalam boiler selain menghasilkan fly ash dan bottom ash juga akan terdeposit abu pada dinding furnance dan permukaan panas lainnya. Peristiwa penumpukan abu pada dinding boiler inilah yang disebut dengan slagging dan fouling. Slagging adalah pembentukan endapan cair atau lebur, yang sebagian di-resolidifikasi pada dinding tungku dan permukaan lain yang terpapar panas radiasi. Umumnya slagging terbentuk pada dinding ruang bakar. Sedangkan Fouling didefinisikan sebagai pembentukan endapan berikatan suhu tinggi pada permukaan penyerap panas konveksi, seperti superheater dan reheater, yang tidak terpapar panas radiasi (babcock \& willcox).

Terbentuknya slagging dan fouling mempengaruhi proses perpindahan panas pada boiler, peningkatan konsumsi bahan bakar, dengan kata lain dapat mengurangi efisiensi dari boiler dan dalam kasus yang ekstrem mengakibatkan pemadaman plant yang tidak terencana untuk proses penghilangan abu dan perbaikan pada boiler. Sehingga dari latar belakang tersebut penulis membahas mengenai potensi pembentukan slagging dan fouling pada boiler berdasar dari kualitas batubara yang digunakan pada proses pembakarannya.

\section{METODE PENELITIAN}

Pertama adalah pengambilan data batubara yang digunakan pada boiler di PLTU Labuan Banten. Data batubara kemudian di uji dengan menggunakan beberapa metode seperti analisa proksimat, ultimat dan ash fusion temperatur. Hasil dari uji metode analisa tersebut kemudian dilakukan perhitungan-perhitungan yang mengacu pada beberapa parameter perhitungan untuk mencari indeks potensi pembentukan slagging dan fouling. Setelahnya 
melakukan analisa berdasarkan data dan hasil perhitungan untuk melihat bagaimana pengaruh dari kualitas batubara terhadap potensi pembentukan deposit abu tersebut. Berikut parameter-parameter untuk menghitung potensi kecepatan pembentukan slagging dan fouling:

\subsection{Ash fusion temperature}

Pegukuran ash fusion temperature merupakan salah satu cara atau metode yang banyak digunakan untuk mengetahui perilaku abu pada batubara pada saat pembakaran. Standar prosedur yang dipakai untuk pengukuran adalah ASTM standart D1857. Pengukuran itu didasar pada peleburan granular abu batu bara dalam bentuk kerucut segitiga sama sisi dengan Panjang $19.1 \mathrm{~mm}$ dan lebar $6.4 \mathrm{~mm}$, dipanaskan dalam ruang bakar terkontrol pada kenaikan suhu $8^{\circ} \mathrm{C}$ per menit. Dan diamati selama penasan dan diperoleh empat parameter temperature sebagai berikut:

1. Initial deformation temperature (IT atau ID) - temperatursaat ujung kerucut mulai melebur atau menunjukkan tanda-tanda deformasi.

2. Softening temperature (ST) - temperatursaat sampel telah berubah bentuk menjadi bentuk bola di mana ketinggian kerucut sama dengan lebar alas $(\mathrm{H}=\mathrm{W})$. Softening temperature umumnya disebut sebagai suhu fusi.

3. Hemispherical temperature (HT) - temperatursaat kerucut telah menyatu menjadi benjolan hemisferis dan tingginya sama dengan setengah lebar dasar $(\mathrm{H}=1 / 2 \mathrm{~W})$.

4. Fluid temperature (FT) - temperatursaat kerucut abu telah meleleh ke lapisan yang hampir rata dengan ketinggian maksimum 0,0625 in. (1,59 mm).

ash fusion temperature $\left({ }^{\circ} \mathrm{C}\right)=\frac{(\mathbf{4} \times \mathbf{I T})+\mathbf{H T}}{\mathbf{5}}$

Ash fusion temperatur yang tinggi menunjukkan bahwa abu yang dilepaskan dalam tungku akan mendingin dengan cepat ke keadaan tidak lengket sehingga meminimalkan potensi terjadinya slagging. Sebaliknya, ash fusion temperature yang rendah menunjukan bahwa abu akan tetap dalam keadaan cair atau plastis lebih lama, menyebabkan lebih banyak permukaan tungku atau permukaan konvektif ke pengendapan potensial

\subsection{Base-Acid Ratio}

Unsur pokok abu batubara dapat diklasifikasikan sebagai basa atau asam. Unsur basa terdiri dari besi, logam alkali tanah kalsium dan magnesium, dan logam alkali natrium dan kalium. Unsur asam terdiri dari silikon, aluminium dan titanium. Basa dan asam cenderung bergabung membentuk senyawa dengan suhu leleh yang lebih rendah. Proporsi relatif dari unsur basa dan asam memberikan indikasi perilaku leleh dan karakteristik viskositas abu 
batubara. Analisis unsur digunakan untuk menghitung persen basa, persen asam dan perbandingan basa dengan asam sebagai berikut:

Untuk abu bituminous

$\%$ Basa

$$
=\frac{\left(\mathrm{Fe}_{2} \mathrm{O}_{3}+\mathrm{CaO}+\mathrm{MgO}+\mathrm{Na}_{2} \mathrm{O}+\mathrm{K}_{2} \mathrm{O}\right) \times 100}{\mathrm{SiO}_{2}+\mathrm{Al}_{2} \mathrm{O}_{3}+\mathrm{TiO}_{2}+\mathrm{Fe}_{2} \mathrm{O}_{3}+\mathrm{CaO}+\mathrm{MgO}+\mathrm{Na}_{2} \mathrm{O}+\mathrm{K}_{2} \mathrm{O}}
$$

$\%$ Asam

$$
\begin{gathered}
=\frac{\left(\mathrm{SiO}_{2}+\mathrm{Al}_{2} \mathrm{O}_{3}+\mathrm{TiO}_{2}\right) \times 100}{\mathrm{SiO}_{2}+\mathrm{Al}_{2} \mathrm{O}_{3}+\mathrm{TiO}_{2}+\mathrm{Fe}_{2} \mathrm{O}_{3}+\mathrm{CaO}+\mathrm{MgO}+\mathrm{Na}_{2} \mathrm{O}+\mathrm{K}_{2} \mathrm{O}} \\
\mathrm{B} / \mathrm{A} \text { ratio }=\frac{\mathrm{Fe}_{2} \mathrm{O}_{3}+\mathrm{CaO}+\mathrm{MgO}_{\mathrm{Na}} \mathrm{O}+\mathrm{K}_{2} \mathrm{O}}{\mathrm{SiO}_{2}+\mathrm{Al}_{2} \mathrm{O}_{3}+\mathrm{TiO}_{2}}
\end{gathered}
$$

Indeks slag $=B / A \times S$

Dimana:

$$
\begin{array}{ll}
\mathrm{B} / \mathrm{A} & =\text { base-acid ratio. } \\
\mathrm{S} & =\text { berat }(\%) \text { sulfur pada dry coal basis }
\end{array}
$$

\subsection{Viscosity}

Ketika abu cair didinginkan, logaritma viskositasnya meningkat secara linear dengan penurunan suhu. Pada titik tertentu, perkembangan menyimpang dari hubungan linear, dan viskositas mulai meningkat lebih cepat karena suhu terus menurun. Transisi ke daerah plastik ini disebabkan oleh pemisahan selektif bahan padat dari cairan, yang dihasilkan dari kristalisasi konstituen titik lebur yang lebih tinggi dari abu. Suhu di mana penyimpangan ini terjadi disebut suhu viskositas kritis (Tcv). Tev bervariasi tergantung pada komposisi abu tetapi biasanya terjadi dalam kisaran antara 100 dan 500 poise. Berakhirnya daerah plastik adalah titik pemadatan, atau titik beku, dari terak. Titik beku biasanya terjadi pada viskositas sekitar 10.000 poise. Untuk kenyamanan dalam membandingkan hubungan viskositas. Temperatur dari berbagai abu, kisaran viskositas 250 hingga 10.000 poise telah didefinisikan sebagai daerah plastik. Suhu di mana daerah plastik di mulai dan kisaran suhu di mana abu adalah plastic, memberikan indikasi kecenderungan slagging. Semakin rendah suhu dalam kisaran ini dan semakin lebar kisaran, semakin besar potensi slagging.

Selanjutnya metodeyang paling akurat untuk memprediksi potensi slagging didasarkan pada hubungan viskositas-suhu abu batubara. Indeks ini (Rvs) berlaku untuk batubara abu bitumen dan lignit; Namun, viskositas abu terukur diperlukan.

$$
R_{v s}=\frac{\left(T_{2500 x i d}\right)-T(10.000 r e d)}{97.5(f s)}
$$

Dimana : 
$T_{250 \text { oxid }}=$ temperatur abu pada saat viskositas sebesar 250 poise

$T_{10000 \text { red }}=$ temperatur abu pada saat viskositas sebesar 10000 poise

FS = correlation factorcor responding to a viscosity of 2000 poise

Nilai $f s$ dapat dicari melalui gambar berikut

Untuk mencari nilai $T_{2500 x i d}$ dan $T_{10000 \text { red }}$ dapat menggunakan persamaan:

$$
\mathrm{T}_{\mu}=\left(\frac{M \times 10^{7}}{(\log \mu)-C}\right)^{\frac{1}{2}}+150
$$

Dimana:

$$
\begin{aligned}
& \mathrm{M}=0,00835 \% \mathrm{SiO}_{2}+0,00601 \% \mathrm{Al}_{2} \mathrm{O}_{3}-0,109 \\
& \mathrm{C}=0,0415 \mathrm{SiO}_{2}+0,0192 \mathrm{Al}_{2} \mathrm{O}_{3}+0,0276 \mathrm{Fe}_{2} \mathrm{O}_{3}+0,016 \mathrm{CaO}-3,92 \\
& \mu=\text { viskositas saat } 250 \text { dan } 10000 \text { poise }
\end{aligned}
$$

\subsection{Fouling Factor}

Fouling factor ini diperoleh dari sintering strength characteristics menggunakan jumlah sodium dalam abu dan base-acid ratio. Parameter ini digunakan untuk mengetahui potensi terjadinya fouling pada abu bituminus[3], berikut adalah rumus mencari faktor fouling:

Abu bituminus

$$
R_{f}=\frac{B}{A} \times \% N a_{2} \mathrm{O}
$$

Dimana:

$$
\begin{array}{ll}
\mathrm{Rf} & =\text { faktor fouling } \\
\mathrm{B} / \mathrm{A} & =\text { rasio asam-basa } \\
\% \mathrm{Na} 2 \mathrm{O} & =\text { persen massa } \mathrm{Na}_{2} \mathrm{O} \text { dari abu. }
\end{array}
$$

\subsection{Sodium content of coal ash}

\begin{tabular}{|c|c|c|c|c|c|}
\hline \multirow{2}{*}{ Aplikasi } & \multirow{2}{*}{ Parameter perhitungan } & \multicolumn{4}{|c|}{ Potensi terbentuk } \\
\hline & & Low & medium & High & Severe \\
\hline $\begin{array}{c}\text { Slagging index } \\
\text { (bituminus) }\end{array}$ & Basis on base acid ratio & slag $<0.6$ & $\begin{array}{c}0.6<\text { slag }< \\
2.0\end{array}$ & $\begin{array}{c}2.0<\text { slag }< \\
2.6\end{array}$ & $\begin{array}{l}2.6< \\
\text { slag }\end{array}$ \\
\hline Slagging index (lignit) & Basis on ash fusion temperature & & & & \\
\hline
\end{tabular}

Beberapa bentuk sodium dalam batubara ketika dibakar pada ruang bakar akan menguap dan selanjutkan terkondensasi pada permukaan panas konveksi yang mana selanjutnya dapat menimbulkan fouling. Parameter ini ditunjukan dengan persen sodium oxide $\left(\% \mathrm{Na}_{2} \mathrm{O}\right) \mathrm{di}$ abu.

Dan berikut adalah standart untuk menentukan potensi pembentukan slagging maupun fouling dari hasil perhitungan parameter-parameter diatas.

Tabel 1. Tingkat kecenderungan terbentuknya slagging dan fouling 


\begin{tabular}{|c|c|c|c|c|c|c|}
\hline & & & $\begin{array}{c}2450< \\
\text { slag }\end{array}$ & $\begin{array}{c}2250<\text { slag }< \\
2450\end{array}$ & $\begin{array}{c}2100<\text { slag }< \\
2250\end{array}$ & $\begin{array}{l}\text { slag }< \\
2100\end{array}$ \\
\hline $\begin{array}{l}\text { Slagging index } \\
\text { (bituminus/lignit) }\end{array}$ & \multicolumn{2}{|r|}{ Basis on viscosity } & slag $<0.5$ & $\begin{array}{c}0.5<\text { slag }< \\
1.0\end{array}$ & $\begin{array}{c}1.0<\text { slag }< \\
2.0\end{array}$ & $\begin{array}{l}2.0< \\
\text { slag }\end{array}$ \\
\hline $\begin{array}{c}\text { Fouling index } \\
\text { (bituminus) }\end{array}$ & \multicolumn{2}{|r|}{ Basis on base acid ratio } & foul $<0.2$ & $\begin{array}{c}0.2<\text { foul }< \\
0.5\end{array}$ & $\begin{array}{c}0.5<\text { foul }< \\
1.0\end{array}$ & $\begin{array}{l}1.0< \\
\text { foul }\end{array}$ \\
\hline & Basis on & when $\mathrm{CaO}+\mathrm{MgO}+\mathrm{Fe}_{2} \mathrm{O}_{3}>20 \%$ & \multicolumn{2}{|c|}{ sodium $<3$} & $\begin{array}{l}3.0<\text { sodium } \\
<6\end{array}$ & $\begin{array}{l}\text { sodium }> \\
6\end{array}$ \\
\hline Fouling index (lignit) & content & when $\mathrm{CaO}+\mathrm{MgO}+\mathrm{Fe}_{2} \mathrm{O}_{3}<20 \%$ & \multicolumn{2}{|c|}{ sodium $<1.2$} & $\begin{array}{l}1.2<\text { sodium } \\
<3\end{array}$ & $\begin{array}{l}\text { sodium }> \\
3\end{array}$ \\
\hline
\end{tabular}

Sumber: (Babcock \& Wilcox 2005)

\section{HASIL DAN PEMBAHASAN}

\subsection{Kecenderungan Slagging pada abu lignit dan bituminus}

Kecenderungan atau potensi pembentukan slagging dapat diketahui melalui perhitungan index slagging dan nilai tersebut akan menentukan apakah Tabel 2. Hasil perhitungan slagging (slagging factor dan ash fusion temperature)

\begin{tabular}{|c|c|c|c|c|}
\hline tipe abu batubara & supplier & $\begin{array}{l}\text { slagging index basis } \\
\text { on base-acid ratio or } \\
\text { slagging factor } \\
\text { (bitumen coal) }\end{array}$ & $\begin{array}{l}\text { slagging index basis } \\
\text { to ash fusion } \\
\text { temperature (lignit } \\
\text { coal) }\end{array}$ & $\begin{array}{l}\text { slagging } \\
\text { propensity }\end{array}$ \\
\hline lignit & arutmin idn & - & 1234 & sedang \\
\hline bituminus & Bukit asam & 0.06 & - & rendah \\
\hline lignit & arutmin idn & - & 1244 & sedang \\
\hline lignit & Bukit asam & - & 1450 & rendah \\
\hline bituminus & arutmin idn & 0.13 & - & rendah \\
\hline bituminus & Bukit asam & 0.06 & - & rendah \\
\hline bituminus & Bukit asam & 0.07 & - & rendah \\
\hline lignit & Bukit asam & - & 1450 & rendah \\
\hline lignit & Bukit asam & - & 1450 & rendah \\
\hline lignit & Bukit asam & - & 1450 & rendah \\
\hline bituminus & Bukit asam & 0.09 & - & rendah \\
\hline bituminus & Bukit asam & 0.07 & - & rendah \\
\hline bituminus & Bukit asam & 0.05 & - & rendah \\
\hline bituminus & titan infra energy & 0.08 & - & rendah \\
\hline bituminus & Bukit asam & 0.08 & - & rendah \\
\hline lignit & bukit asam & - & 1450 & rendah \\
\hline
\end{tabular}




\begin{tabular}{|c|c|c|c|c|}
\hline bituminus & bukit asam & 0.08 & - & rendah \\
\hline
\end{tabular}

kecenderungan terbentuknya ringan, sedang, tinggi, atau pada tingkatan yang parah mengacu pada standar ASTM (American Standart Testing and Material). Untuk menentukan potensi terbentuknya slagging dapat diketahui melalui beberapa parameter, parameter base-acid ratio (slagging factor) untuk abu bituminus dan ash fusion temperature untuk jenis abu lignit. Adapun parameter untuk mengetahui potensi terbentuknya slagging untuk dua jenis abu bitumen dan lignit menggunakan parameter viskositas. Pada Tabel 2 merupakan hasil perhitungan dan penentuan indeks dan potensi terbentuknya slagging Tabel 3. Hasil perhitungan slagging (viskositas)

\begin{tabular}{|c|c|c|c|c|c|c|c|}
\hline \multirow{2}{*}{$\begin{array}{l}\text { Tipe abu } \\
\text { batubara }\end{array}$} & \multirow[t]{2}{*}{ supplier } & $\mathrm{T}_{250}$ & $\mathrm{~T}_{10000}$ & $\mathrm{~T}_{2000}$ & \multirow[t]{2}{*}{$f_{S}$} & \multirow{2}{*}{$\begin{array}{c}\text { slagging } \\
\text { index (Rvs) }\end{array}$} & \multirow{2}{*}{$\begin{array}{c}\text { slagging } \\
\text { propensity }\end{array}$} \\
\hline & & units $\left({ }^{\circ} \mathrm{C}\right)$ & units $\left({ }^{\circ} \mathrm{C}\right)$ & units $\left({ }^{\circ} \mathrm{C}\right)$ & & & \\
\hline lignit & arutmin idn & 1289,7 & 1004,84 & 1100,32 & 1,4 & 1,3 & High \\
\hline bituminus & Bukit asam & 1268,8 & 1101,91 & 1165 & 1,9 & 0,68 & medium \\
\hline lignit & arutmin idn & 1233,89 & 992,61 & 1076,35 & 1,3 & 1,25 & High \\
\hline lignit & Bukit asam & 1249,04 & 1088,92 & 1149,68 & 1,8 & 0,69 & medium \\
\hline bituminus & arutmin idn & 1609,81 & 1212,93 & 1342,11 & 4,8 & 0,51 & medium \\
\hline bituminus & Bukit asam & 1237,96 & 1087,65 & 1145,15 & 1,8 & 0,66 & medium \\
\hline bituminus & Bukit asam & 1253,6 & 1092,38 & 1153,53 & 1,8 & 0,7 & medium \\
\hline lignit & Bukit asam & 1206,6 & 1055,76 & 1113,18 & 1,4 & 0,85 & medium \\
\hline lignit & Bukit asam & 1210,21 & 1064,14 & 1120,5 & 1,5 & 0,77 & medium \\
\hline lignit & Bukit asam & 1201,21 & 1056,14 & 1111,65 & 1,4 & 0,82 & medium \\
\hline bituminus & Bukit asam & 1240,88 & 1078,33 & 1139,8 & 1,6 & 0,79 & medium \\
\hline bituminus & Bukit asam & 1237,28 & 1074,4 & 1135,93 & 1,6 & 0,79 & medium \\
\hline bituminus & Bukit asam & 1210,7 & 1064,51 & 1120,45 & 1,5 & 0,77 & medium \\
\hline bituminus & $\begin{array}{l}\text { titan infra } \\
\text { energy }\end{array}$ & 1266,98 & 1100,12 & 1163,19 & 1,75 & 0,74 & medium \\
\hline bituminus & Bukit asam & 1224,7 & 1064,75 & 1125,24 & 1,5 & 0,83 & medium \\
\hline lignit & bukit asam & 1197,25 & 1053,73 & 1108,7 & 1,4 & 0,81 & medium \\
\hline bituminus & bukit asam & 1211,05 & 1056,69 & 1115,28 & 1,5 & 0,8 & medium \\
\hline
\end{tabular}

pada dua jenis abu yang berbeda menggunakan parameter basa-asam rasio dan ash fusion temperatur, sekilas kita lihat ada dua data yang menunjukan bahwa potensi slagging yang 
tinggi pada abu jenis lignit pada 2 data yang menghasilkan nilai ash fusion temperature yang cukup rendah $1234^{\circ} \mathrm{C}$ dan $1244^{\circ} \mathrm{C}$. Sementara potensi slagging pada abu bituminous memiliki kecenderungan yang rendah dengan nilai indeks basa-asam rasio berkisar dari 0,05 sampai 0,13. Namun, sulit untuk membandingkan potensi pembentukan slagging abu bituminus dan lignit pada hasil tersebut karena pada perhitungan tersebut digunakan parameter perhitunan yang berbeda. Maka perhitungan menggunakan parameter viskositas digunakan untuk membandingkan antara dua jenis abu yang berbeda. Rata-rata index slagging abu lignit lebih tinggi dibanding abu bituminus berdasarkan hasil perhitungan menggunakan parameter viskositas pada Tabel 3, hasil ini sama dengan yang ditunjukan oleh perbandingan hasil dari perhitungan menggunakan parameter basa-asam rasio dengan ash fusion temperature terhadap masing-masing jenis abu batubara lignit dan bituminous yang mana memang abu lignit potensi pembentukan slagging yang lebih tinggi Rata-rata index slagging abu lignit lebih tinggi dibanding abu bituminus berdasarkan hasil perhitungan menggunakan parameter viskositas pada Tabel 3, hasil ini sama dengan yang ditunjukan oleh perbandingan hasil dari perhitungan menggunakan parameter basa-asam rasio dengan ash fusion temperature terhadap masing-masing jenis abu batubara lignit dan bituminous yang mana memang abu lignit potensi pembentukan slagging yang lebih tinggi

\subsubsection{Pengaruh kangdungan besi terhadap kecenderungan slagging}

Salah satu penyebab tingginya indeks slagging adalah kandungan besi dalam batubara terutama pada jenis abu bituminous karena batubara dengan jenis abu bituminous umumnya memiliki kandungan besi yang lebih tinggi dibanding batubara dengan abu lignit. Kandungan $\mathrm{Fe}_{2} \mathrm{O}_{3}$ dalam data abu bituminus menunjukan karakteristik pada Gambar 1. Pada gambar tersebut menujukan besar nilai $\mathrm{Fe}_{2} \mathrm{O}_{3}$ mempengaruhi besar nilai indeks slagging pada perhitungan parameter basa-asam rasio, nilai $\mathrm{Fe}_{2} \mathrm{O}_{3}$ yang besar menghasilkan nilai indeks slagging yang besar.

Tabel 4. Kandungan $\mathrm{Fe}_{2} \mathrm{O}_{3}$ pada abu bituminus

\begin{tabular}{|c|c|c|c|}
\hline $\begin{array}{c}\text { tipe abu } \\
\text { batubara }\end{array}$ & supplier & $\mathrm{Fe}_{2} \mathrm{O}_{3}$ & $\begin{array}{c}\text { slagging index basis } \\
\text { on base-acid ratio or } \\
\text { slagging factor } \\
\text { (bitumen coal) }\end{array}$ \\
\hline Bituminus & Bukit asam & 4,62 & 0,06 \\
\hline Bituminus & arutmin idn & 14,19 & 0,13 \\
\hline Bituminus & Bukit asam & 3,59 & 0,06 \\
\hline Bituminus & Bukit asam & 4,54 & 0,07 \\
\hline
\end{tabular}




\begin{tabular}{|c|c|c|c|}
\hline bituminus & Bukit asam & 4,89 & 0,09 \\
\hline bituminus & Bukit asam & 4,90 & 0,07 \\
\hline bituminus & Bukit asam & 3,37 & 0,05 \\
\hline bituminus & $\begin{array}{c}\text { titan infra } \\
\text { energy }\end{array}$ & 4,70 & 0,08 \\
\hline bituminus & Bukit asam & 4,79 & 0,08 \\
\hline bituminus & bukit asam & 4,30 & 0,08 \\
\hline
\end{tabular}

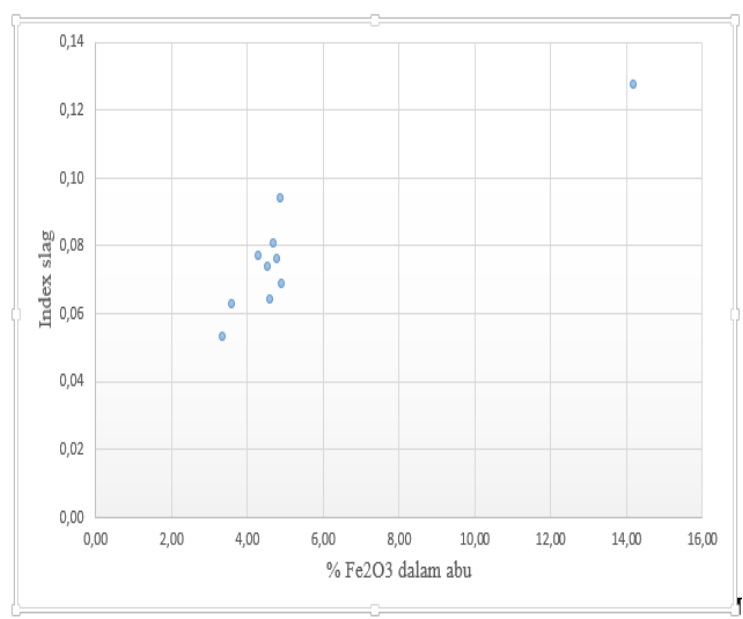

Gambar 1. Pengaruh unsur besi terhadap potensi pembentukan slagging abu bituminous

3.1.2 Pengaruh kandungan kalsium dan magnesium terhadap kecenderungan slagging Kalsium dan magnesium umumnya lebih banyak terkandung pada abu jenis lignit, dibandingkan abu bituminous yang cenderung memiliki kandungan besi yang lebih banyak. Kalsium dan magnesium pada tingkat atau nilai yang tinggi memungkinkan untuk menurunkan nilai ash fusion temperature pada saat teroksidasi menjadi $\mathrm{CaO}$ dan $\mathrm{MgO}$. Nilai ash fusion temperature yang rendah akan mengakibatkan abu tetap dalam keadaan cair atau plastis lebih lama, menyebabkan lebih banyak permukaan tungku atau permukaan konvektif ke pengendapan potensial, yang mana lebih banyak slag. Karakteristik dari $\mathrm{CaO}$ dan $\mathrm{MgO}$ ini dapat dilihat pada Gambar 2, nilai ash fusion temperature akan semakin rendah seiring dengan bertambahnya nilai kandungan $\mathrm{CaO}$ dan $\mathrm{MgO}$.

\subsection{Kecenderungan fouling abu lignit dan bituminous}

Penentuan potensi pembentukan fouling untuk abu bituminous dapat ditentukan melalui parameter basa-asam rasio dikalikan dengan $\% \mathrm{Na} 2 \mathrm{O}$ dalam abu sedangkan untuk abu lignit dapat diketahui menggunakan parameter \%Na2O yang terkandung dalam abu. Pada hasil 
perhitungan Tabel 5 memperlihatkan hasil indeks dari abu bituminus cenderung memiliki tingkatan fouling yang rendah sampai sedang, dan pada abu lignit memiliki potensi pembentukan fouling rendah dan tinggi untuk beberapa data.

Tabel 5. Hasil perhitungan fouling abu bituminus dan lignit

\begin{tabular}{|c|c|c|c|c|c|}
\hline tipe abu batubara & supplier & $\mathrm{Na}_{2} \mathrm{O}$ & $\begin{array}{l}\text { fouling index basis } \\
\text { base-acid ration and } \\
\text { sodium (bituminus } \\
\text { coal) }\end{array}$ & $\begin{array}{l}\text { fouling index } \\
\text { basis sodium } \\
\text { content on ash } \\
\text { (lignit coal) }\end{array}$ & fouling propensity \\
\hline lignit & arutmin idn & 0,06 & - & 0,06 & rendah \\
\hline bituminus & Bukit asam & 0,88 & 0,09 & - & rendah \\
\hline lignit & arutmin idn & 0,20 & - & 0,2 & rendah \\
\hline lignit & Bukit asam & 0,48 & - & 0,48 & rendah \\
\hline bituminus & arutmin idn & 0,20 & 0,09 & - & rendah \\
\hline bituminus & Bukit asam & 0,82 & 0,08 & - & rendah \\
\hline bituminus & Bukit asam & 0,87 & 0,11 & - & rendah \\
\hline lignit & Bukit asam & 2,54 & - & 2,54 & high \\
\hline lignit & Bukit asam & 2,37 & - & 2,37 & high \\
\hline lignit & Bukit asam & 2,73 & - & 2,73 & high \\
\hline bituminus & Bukit asam & 1,96 & 0,26 & - & sedang \\
\hline bituminus & Bukit asam & 2,12 & 0,29 & - & sedang \\
\hline bituminus & Bukit asam & 2,36 & 0,27 & - & sedang \\
\hline bituminus & titan infra energy & 0,45 & 0,05 & - & rendah \\
\hline bituminus & Bukit asam & 2,13 & 0,29 & - & sedang \\
\hline lignit & bukit asam & 2,99 & - & 2,99 & high \\
\hline bituminus & bukit asam & 2,22 & 0,31 & - & sedang \\
\hline
\end{tabular}

\subsubsection{Pengaruh kandungan natrium terhadap kecenderungan fouling}

Potensi pembentukan fouling dipengaruhi oleh logam alkali, natrium dan kalium terutama sangat dipengaruhi oleh unsur natrium baik untuk abu bituminous maupun lignit. Parameter basa-asam rasio dan total $\mathrm{Na} 2 \mathrm{O}$ dalam abu digunakan untuk mengembangkan indeks fouling yang saat ini digunakan untuk batubara dengan abu bitumen. Hal serupa tidak berlaku untuk abu lignitik dengan kandungan basa tinggi ( $\mathrm{CaO}, \mathrm{MgO})$. Namun, dapat ditentukan dengan parameter total kandungan natrium dalam abu. Parameter-parameter tersebut dapat menggambarkan karakteristik dari pengaruh besarnya nilai unsur $\mathrm{Na} 2 \mathrm{O}$ terhadap kecenderungan terbentuknya fouling. 


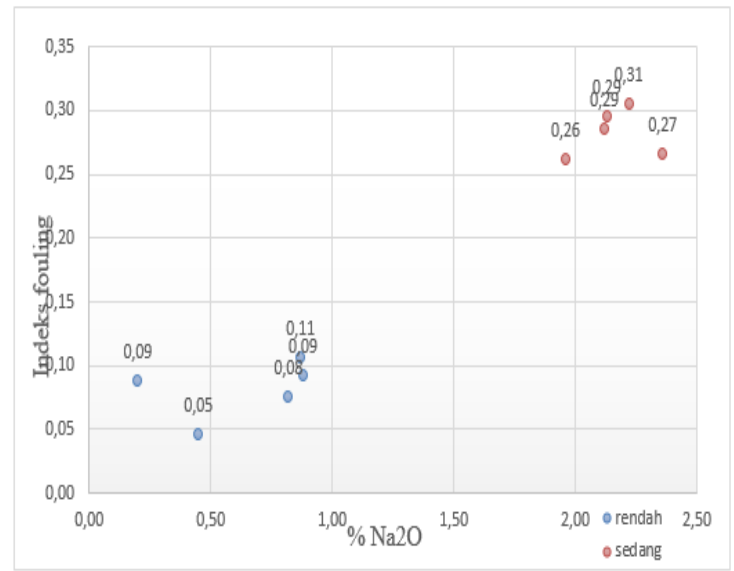

Gambar 2. Pengaruh unsur $\mathrm{Na} 2 \mathrm{O}$ terhadap indeks fouling abu bituminous

Pada Gambar 2 dan Gambar 3 yang menunjukan karakteristik pengaruh Na2O terhadap besarnya nilai indeks fouling, bahwa nilai $\mathrm{Na} 2 \mathrm{O}$ yang besar akan menghasilkan nilai indeks yang besar, dalam artian maka potensi terbentuknya fouling semakin besar. Pada hasil perhitungan Tabel 5 memperlihatkan adanya kesamaan indeks pada abu bituminous dan lignit, yaitu pada beberapa data menunjukan hasil indeks dimana potensi fouling nya berada pada tingkatan rendah. Hasil tersebut dapat dujelaskan jika melihat karakteristik pengaruh $\mathrm{Na} 2 \mathrm{O}$ terhadap pembentukan fouling, data perhitungan dari kedua jenis abu batubara tersebut memiliki \% Na2O yang rendah sehingga menghasilkan nilai indeks yang rendah. Namun, umumnya kandungan $\mathrm{Na} 2 \mathrm{O}$ dalam abu lignit memiliki nilai yang lebih besar daripada abu bituminous sehingga batubara dengan jenis abu lignit seringkali menyebabkan masalah fouling yang cukup parah seperti yang ditunjukan data hasil perhitungan Tabel 5 nilai kandungan unsur Na2O yang menyebabkan indeks fouling yang parah pada abu lignit yaitu 2,37; 2,54; 2,73; sampai 2,99. Sementara pada abu bituminous memiliki kandungan yang lebih rendah sehingga indeksnya juga rendah.

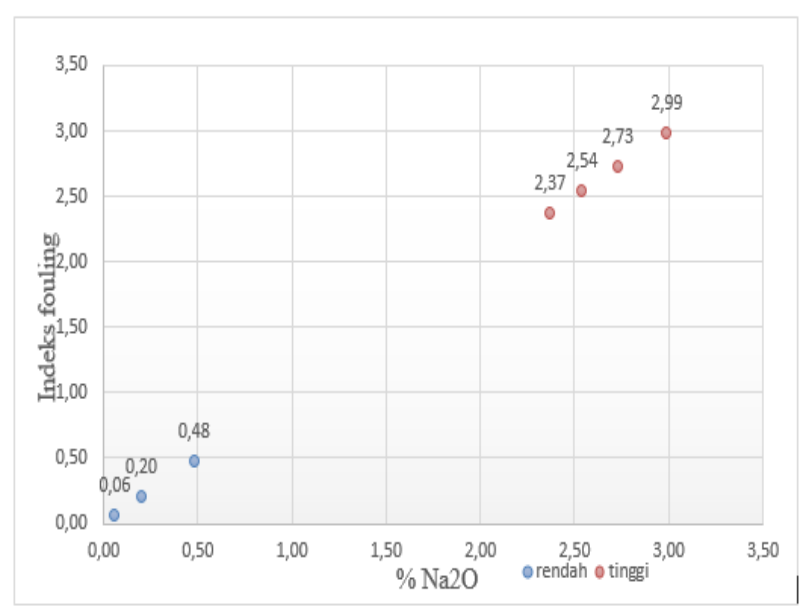

Gambar 3. Pengaruh unsur Na2O terhadap indeks fouling abu lignit 


\section{KESIMPULAN}

Kandungan unsur Fe2O3 berpengaruh pada potensi pembentukan slagging untuk batubara dengan jenis abu bituminus, untuk jenis abu lignit unsur $\mathrm{CaO}$ dan $\mathrm{MgO}$ yang mempengaruhi besar nilai indeks potensi pembentukan slagging. Sementara untuk potensi pembentukan fouling, unsur $\mathrm{Na} 2 \mathrm{O}$ menjadi unsur yang berpengaruh baik pada batubara dengan jenis abu bituminus maupun lignit. Batubara dengan jenis abu lignit cenderung memiliki indeks nilai potensi pembentukan slagging dan fouling yang lebih tinggi dibandingkan dengan batubara dengan jenis abu bituminous

\section{DAFTAR PUSTAKA}

K. rayaprolu, Boilers for power and prosses, U.S.A.: CRC Press, 2009.

j. li, "effect of coal blending on ash fouling and slagging in pulverized coal fired supercritical (SC) and ultra-supercritical (UC) power planr," thesis university of western australia, australia, 2016.

Babcock and Wilcox, Steam its generation and use, 41 ed., J. B. K. a. S. C. Stultz, Ed., Barberton, ohio: Babcock and Wilcox, 2005.

Cahyadi, PLTU batubara supercritikal yang efisien, Tanggerang selatan: BPPT , 2015

D. S. rao, Minerals and coal prosses calculation, UK: CRC Press, 2016.

B. G. Miller, Coal energy system, U.S.A., 2005.

J. G. Speight, Handbook of coal analysis, 2 ed., vol. 182, new jersey: Wiley, 2015.

H. Spielthoff, Power generation from solid fuel, New York: Springer, 2010.

E. C. Winegartner, coal fouling and slagging parameters, U.S.A, 1974. 